\title{
Study on energy loss and thermal environment through door open while air conditioner running
}

\author{
Sihwan Lee ${ }^{1, *}$ \\ ${ }^{1}$ Shinshu University, Department of Architecture, 4-17-1 Wakasato Nagano, Japan
}

\begin{abstract}
While air conditioner is running, opening doors and windows is a great way to reduce operating efficiency and undermine the air conditioning system's ability to bring the indoor to a comfortable temperature. The purpose of this study is to evaluate the heat loss and thermal environment through the door open while air conditioner running. To achieve this goal, using full-scale measurement with the commercial store during the cooling period, the infiltration rate, thermal environment and energy consumption of air conditioners with door opened and door closed state were measured. The measured results show that the infiltration rate at the door opened state was increased by about 21.3 times compared to the door closed state. When the set temperature of the air conditioner was $24{ }^{\circ} \mathrm{C}$, the room temperature in the opening gate cooling was measured to be about $5{ }^{\circ} \mathrm{C}$ higher than the closing gate cooling. However, the energy consumption was measured approximately $12 \mathrm{kWh} /$ day and there was no difference with door state. This means that the energy consumption is not increased if the indoor air temperature would not reach the set point temperature of air conditioner.
\end{abstract}

\section{Introduction}

Commercial store such as shop in district, department store, convenience store, outdoor cafes, restaurants, etc., is often business leaving doors and opening windows while air conditioner is running to attract more customers and to increase sales. However, that brings a great way to reduce operating efficiency and undermine the air conditioning system's ability to bring the indoor to a comfortable temperature. It also increases the cooling and heating load due to the air leakage caused by the temperature difference. Figure 1 shows an infrared thermal image in case of door open while air conditioner running in commercial stores. If there is a significant temperature difference between indoor air and outdoor air, the air leakage will increase significantly.

To solve the problem, many facilities for entrance with vestibule, revolving door, entry heater, door closer, air curtain and shopping arcade are utilized to reduce the energy loss [1]. Several countries have established policies to impose fines on commercial store with the door open while air conditioner running. New York in the United States is a law [2] passed in 2015 to keep store and restaurant doors closed when their air conditioning is on. According to law, violators face fines of $\$ 250$ for a first offense and up to $\$ 1,000$ for an egregious violation.

The purpose of this study is to investigate the infiltration rate and energy loss across the door in a commercial store. To achieve this goal, the infiltration rate across the door were investigated quantitatively by actual measurement in summer and the results were compared with the steady-state calculation method. Moreover, the heat loss characteristic and the indoor thermal environment also investigated.

\section{Methods}

The target store is a flower shop located in Nagano city $\left(36^{\circ} 38^{\prime} 54.9^{\prime \prime} \mathrm{N}, 138^{\circ} 11^{\prime} 39.1^{\prime \prime} \mathrm{E}\right)$, Japan. Figure 2 shows a three-dimensional schematic model of the store. The store has a total floor area of $36.3 \mathrm{~m}^{2}$, a volume of $89.6 \mathrm{~m}^{3}$ (actual volume: $65.0 \mathrm{~m}^{3}$ (excluding furniture, equipment, etc.)). The indoor space is consisted in a sales space, a cash register, and a work space. There are 2 openings in the store, the main entrance $\left(3.52 \mathrm{~m}^{2}\right)$ in the west side, the sub entrance $\left(1.61 \mathrm{~m}^{2}\right)$ with a semi-circular window $(0.37$ $\mathrm{m}^{2}$ ) in the northwest side. Figure 3 shows photographs of the main entrance and the indoor status.

To investigate the infiltration rate, energy loss and thermal environment of the store, the measurement conditions are shown in Table 1. The measurement cases are 2 cases, in case of opened door and closed the door. The measurement is conducted from 10:00 to 19:00 which is the opening hours to business. The data analysis is used just 2 days acquired data in a similar outdoor thermal condition

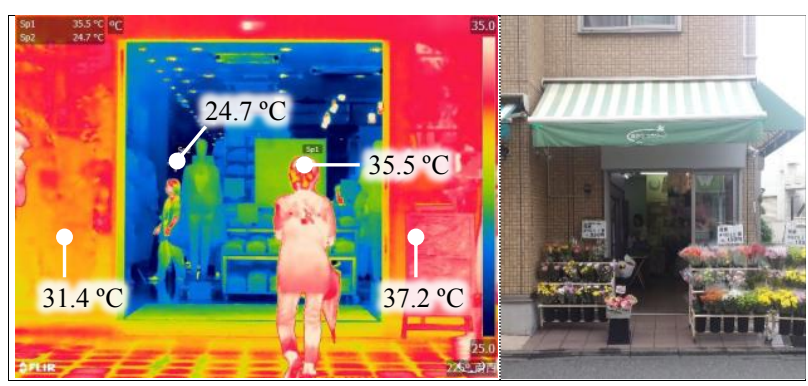

Fig. 1. Infrared thermal image and a status of door open while air conditioner running in a commercial store.

\footnotetext{
* Corresponding author: shany@shinshu-u.ac.jp
} 
comparatively as shown in Fig. 4. Figure 4 shows the infrared thermal image of surface temperature at the main entrance at 15:00. By comparison with these images, the outdoor wall temperature was similar on analysis days, 1819 July 2018. The air conditioning for a cooling operation is conducted by 2 air conditioners with a cooling capacity of $3.6 \mathrm{~kW}$ (rated power consumption: $0.74 \mathrm{~kW}$ ), and the setpoint temperature is $26{ }^{\circ} \mathrm{C}$. Measurement items are the infiltration rate, the indoor and outdoor temperature, external wall surface temperature, and electric power consumption.

\subsection{Infiltration rate across the door}

The infiltration rate was measured by dispersing sulfur hexafluoride $\left(\mathrm{SF}_{6}\right)$ as a tracer gas. Because the flower shop has many flowers and plants, the $\mathrm{SF}_{6}$ was used as a tracer gas instead of the $\mathrm{CO}_{2}$ in consideration of the possibility of fluctuation of flowers and plants. Among the tracer gas dilution method [3], we used the constant concentration test method, in which the tracer injection is changed so that the indoor concentration becomes constant as shown in Fig. 5. Measurement of the $\mathrm{SF}_{6}$ gas concentration was carried out by constantly monitoring the tracer gas concentration in the room using a real-time multi-gas monitor (INNOVA 1312) through plastic tubes. In addition, the tracer injection rate was performed with an indoor concentration as a target value of 10 ppm using a multipoint doser and sampler (INNOVA 1303). The tracer injection point was set to a plurality so that the concentration in the store was sufficiently uniform. The infiltration rate is calculated by Eq. 1 .

$$
\mathrm{Q}=\mathrm{G} / \overline{\mathrm{c}}
$$

Here, $Q\left[\mathrm{~m}^{3} / \mathrm{s}\right]$ is the infiltration rate out of the indoor area, $G\left[\mathrm{~m}^{3} / \mathrm{s}\right]$ is the steady rate of tracer injection, $\bar{c}$ [ppm] is the time-mean concentration.

\subsection{Thermal environment and energy consumption}

The thermal environment in the store is investigated with cases by measuring air temperature. Thermal recorders (T\&D Corporation, TR-72wf, -10 to $60^{\circ} \mathrm{C}$ ) are used for temperature data recording. To investigate the difference of the energy loss by opening and closing the door, the electric power consumption of each device is also examined by measuring the electric current and voltage using clamps and clamp loggers (HIOKI LR5051) as shown in Fig. 6.

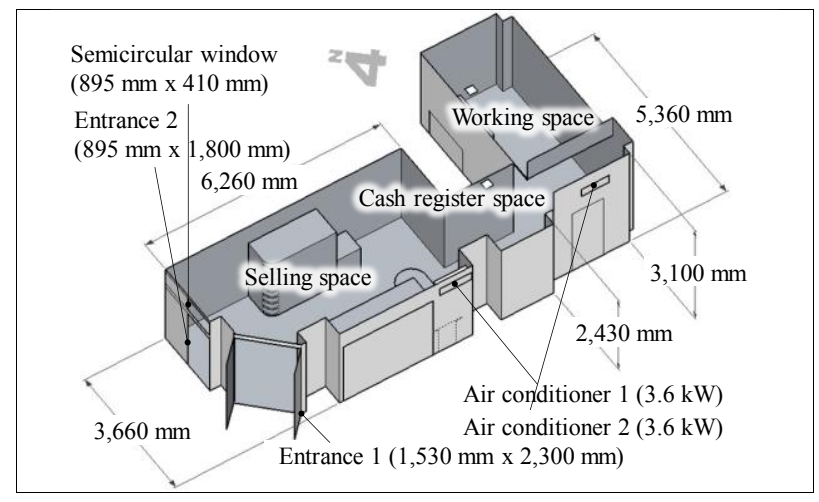

Fig. 2. Schematic model of target store.

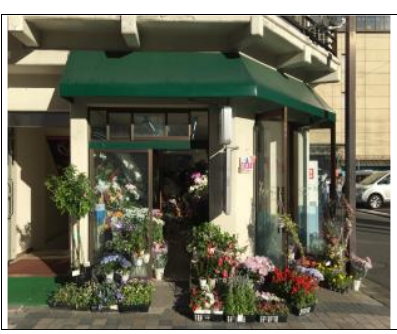

(a) Entrance

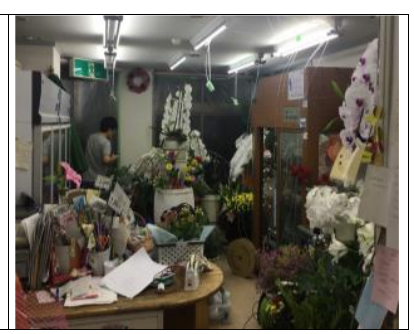

(b) Indoor status
Fig. 3. Photograph of target store.

Table 1. Measurement cases.

\begin{tabular}{|c|c|}
\hline Item & Contents \\
\hline \multirow{2}{*}{ Cases } & Door opened case (10:00 19:00, 18. July 2018) \\
\hline & Door closed case (10:00 19:00, 19. July 2018) \\
\hline Cooling capacity & Air conditioner (Cooling capacity: $3.6 \mathrm{~kW}$ x 2 ea) \\
\hline Measurements & $\begin{array}{c}\mathrm{SF}_{6} \text {, Infrared thermal image, Temperature, } \\
\text { Humidity, Electric power consumption }\end{array}$ \\
\hline
\end{tabular}

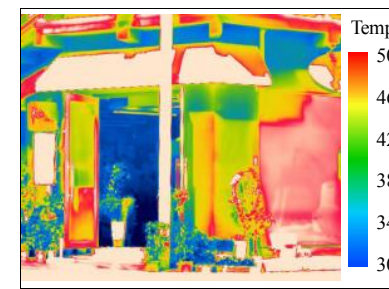

(a) Door opened case

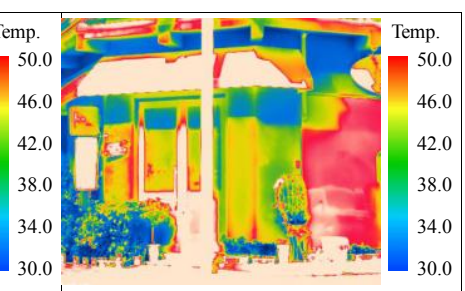

(b) Door closed case
Fig. 4. Surface temperature at the main entrance at 15:00.

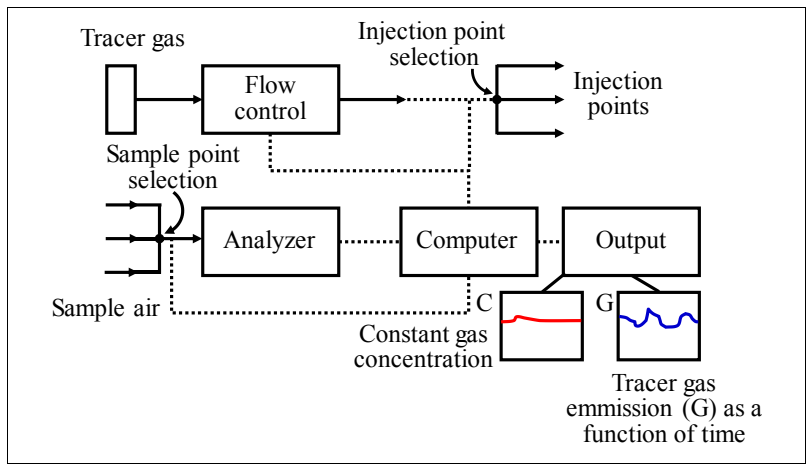

Fig. 5. Constant concentration test method.

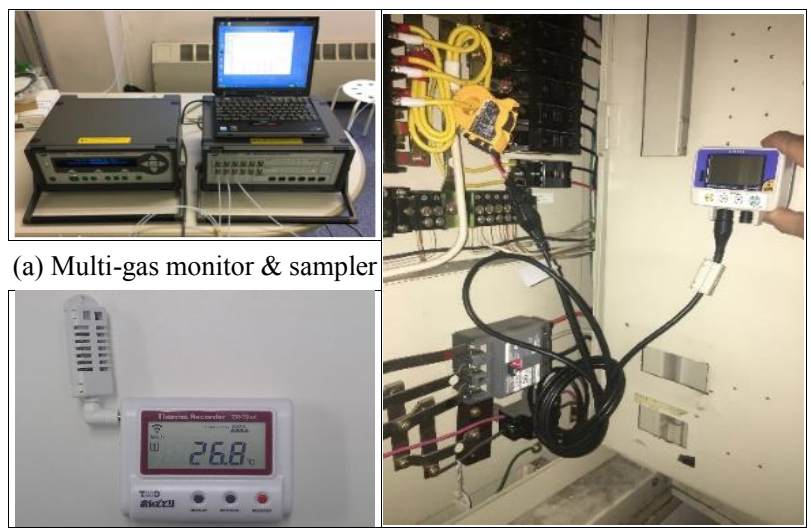

(b) Thermal recorder

(a) Clamp logger

Fig. 6. Measured devices. 


\section{Results}

\subsection{Results of infiltration rate across the door}

Figure 7 shows the measurement results of infiltration rate compared with the case of the closed door and the opened door. The infiltration rate across the door in door opened case was measured approximately $1,414.6 \mathrm{~m} 3 / \mathrm{h}$ as the average value. In case of the closed door, the infiltration rate was measured approximately $66.5 \mathrm{~m} 3 / \mathrm{h}$. As a result, it was found that the infiltration rate in the opened door case was increased by about 21.3 times compared with the case of the closed door.

\subsection{Thermal environment and energy consumption}

Figure 8 shows the transition of indoor and outdoor temperature in case of the closed door and in case of the opened door. When the set-point temperature of the air conditioner is $26{ }^{\circ} \mathrm{C}$, the indoor temperature of the store in case of the opened door is measured as $35^{\circ} \mathrm{C}$ to $27^{\circ} \mathrm{C}$ and in case of the closed door is measured as $31{ }^{\circ} \mathrm{C}$ to $25^{\circ} \mathrm{C}$. Although the indoor temperature of the store has not maintained the set-point temperature of $26^{\circ} \mathrm{C}$ in both cases, the temperature in case of the opened door is more increased than in case of the closed door.

Figure 9 shows the indoor temperature distribution of the store in case of the opened door and the closed door. When the outdoor air temperature was the highest, at 15:00, the result shows that the sales space is maintained approximately $34{ }^{\circ} \mathrm{C}$ to $35{ }^{\circ} \mathrm{C}$ in case of opened door. Whereas in case of closed door, the selling space is maintained at the temperature of about 28 to $30{ }^{\circ} \mathrm{C}$. That is a reason that increasing of the infiltration rate with increasing the temperature difference is caused thermal environment in the store. In case of the opened door, it is not stable to $26^{\circ} \mathrm{C}$, because the cooling capacity of the air conditioner is not enough. That is also probably because of not only the cooling capacity of the air conditioner but also the problem with the arrangement position and airflow direction of the air conditioner.

Figure 10 shows the electric power consumption of 2 air conditioners and socket. As the results, the electric power consumption of 2 air conditioners was measured approximately $12.21 \mathrm{kWh} /$ day in case of the opened door (no consideration of socket power consumption) and 12.04 $\mathrm{kWh} /$ day in case of the closed door (no consideration of socket power consumption). It had not a big difference with evaluated cases unlike thermal environment. This is a similar reason like indoor thermal environment that the cooling capacity of the air conditioner was insufficient to remove the cooling load of the store. It means that the air conditioner was full operated at all time, thus it also means that the electric power consumption is not increased when the indoor air temperature is not reached the set-point temperature of the air conditioner.

\section{Discussion}

Pham and Oliver [4] proposed a steady-state equation of natural convection through single vertical rectangular

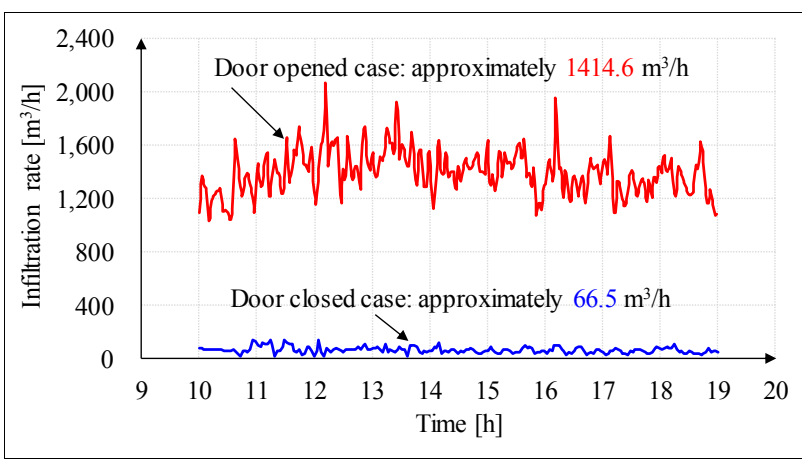

Fig. 7. Measurement result of infiltration rate.

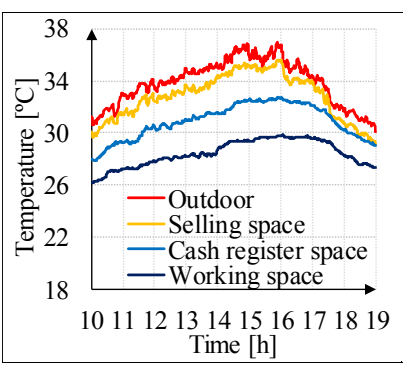

(a) Door opened case

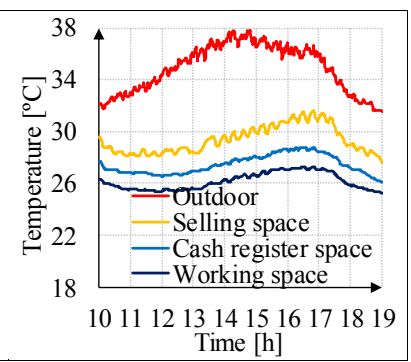

(b) Door closed case
Fig. 8. Measurement result of air temperature.

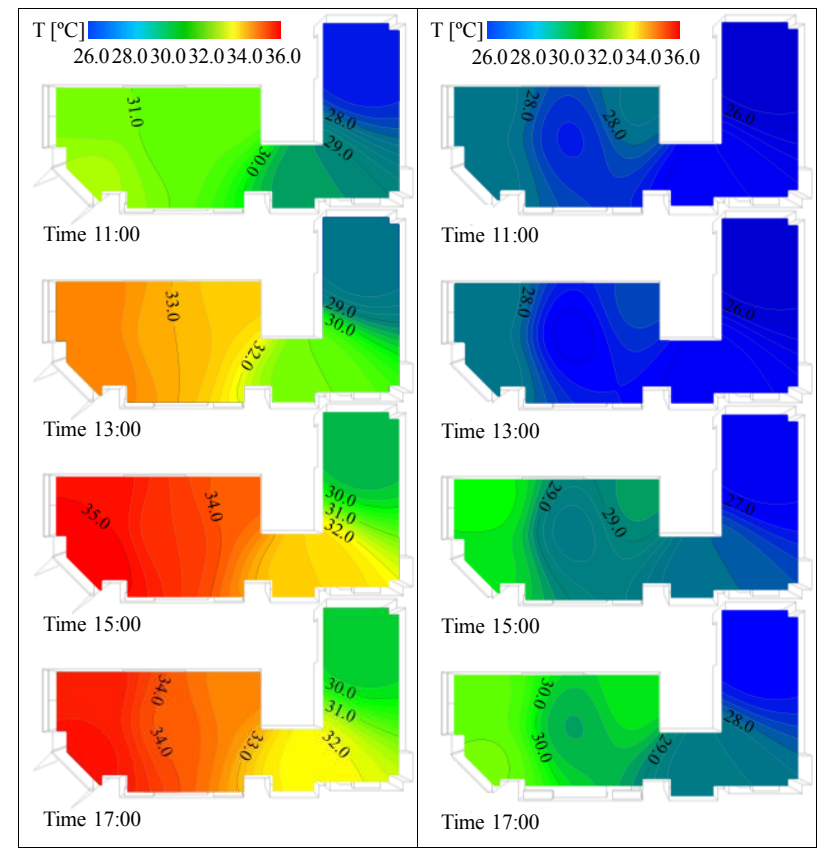

(a) Door opened case

(b) Door closed case

Fig. 9. Measurement result of temperature.

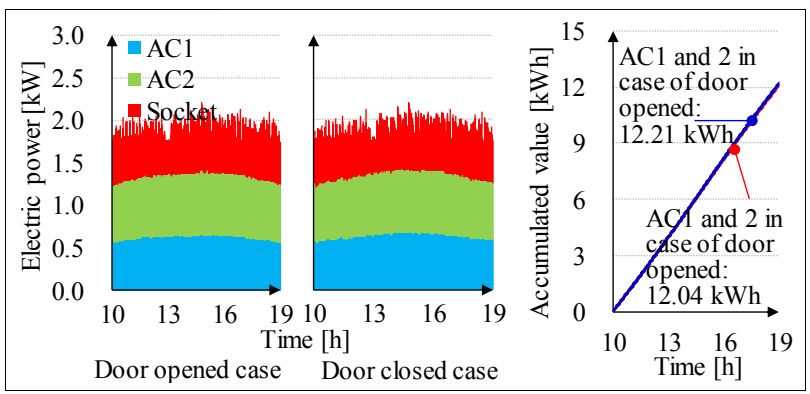

Fig. 10. Electric power consumption. 
openings by experiments on airflow through refrigerated room doors as shown in Eq. 2.

$$
\mathrm{Q}=0.226 \mathrm{~A}(\mathrm{gH})^{0.5}\left[\frac{\rho_{\mathrm{i}}-\rho_{\mathrm{o}}}{\rho_{\mathrm{i}}}\right]^{0.5}\left[\frac{2}{1+\left(\rho_{\mathrm{o}} / \rho_{\mathrm{i}}\right)^{0.333}}\right]^{1.5}
$$

Here, $A\left[\mathrm{~m}^{2}\right]$ is the opening area, $g\left[\mathrm{~m} / \mathrm{s}^{2}\right]$ is the gravity acceleration, $H[\mathrm{~m}]$ is the height of opening, $\rho\left[\mathrm{kg} / \mathrm{m}^{3}\right]$ is the air density. The subscript ' $i$ ' used in this equation means indoor or cool climate area, and ' $O$ ' means outdoor or hot climate area.

Measured infiltration rates were compared to the calculated results to verify that the Pham and Oliver's equation were consistent with the actual findings. Figure 11 shows the comparison between the measured value and the theoretical value of the infiltration rate by using Eq. 2. The average value of the theoretical infiltration rate in case of the opened door was calculated approximately $1,148.2 \mathrm{~m}^{3} / \mathrm{h}$. Although the infiltration rate was smaller than the measurement value because the theoretical value is not considered the effect of wind pressure, the transition of the infiltration rate for a day was the same pattern with the measured value.

Using the infiltration rate by using Pham and Oliver's equation, the infiltration load is also considered when the indoor temperature is maintained at $26{ }^{\circ} \mathrm{C}$. Pham and Oliver's equation is an effective way to calculate infiltration load because the infiltration rate was almost the same as the actual measurement value and the indoor temperature could not be maintained at the set-point temperature at all time in actual measurement. Figure 11 shows the comparison between the infiltration load required to maintain the indoor temperature at $26{ }^{\circ} \mathrm{C}$ and the infiltration load generated from the actual measurement. The infiltration load is calculated as $9.12 \mathrm{~kW}$ by using Pham and Oliver's equation when the indoor temperature is maintained at $26{ }^{\circ} \mathrm{C}$. Whereas the infiltration load in case of the opened door was measured approximately $0.57 \mathrm{~kW}$ in actual measurement because the indoor temperature was maintained higher than $26{ }^{\circ} \mathrm{C}$. Therefore, to business with the door open while air conditioner running in summer, removing process of infiltration load is needed at least $9.12 \mathrm{~kW}$ in the store. It means that it is necessary for additional consideration of the infiltration load with opening door to design for air conditioning.

\section{Conclusions}

From the point of view to reduce energy consumption, door open while air conditioner running on buildings have a problem. This paper had investigated the infiltration rate and energy loss across the door in the commercial store by actual measurement. The following conclusions can be drawn from the results of the study:

(1) The infiltration rate across the door while air conditioner running for cooling was about 21.3 times larger than the case of the closed door on the target store.

(2) The infiltration rate in case of the opened door using Pham and Oliver's equation was consistent with the actual findings.

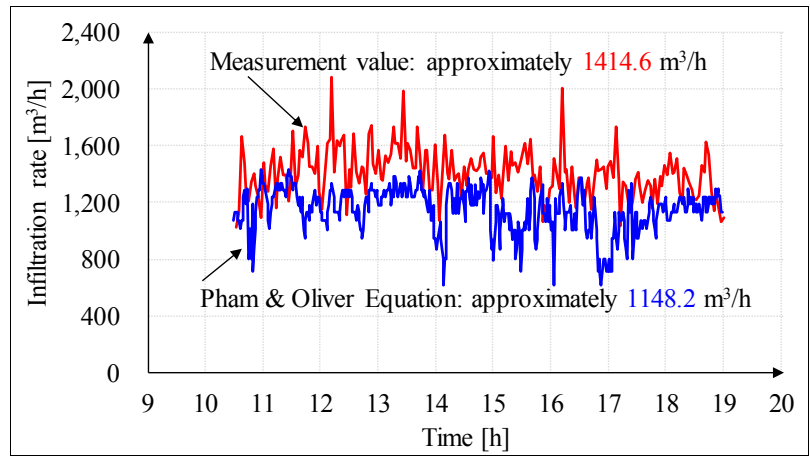

Fig. 11. Comparison with Pham \& Oliver equation.

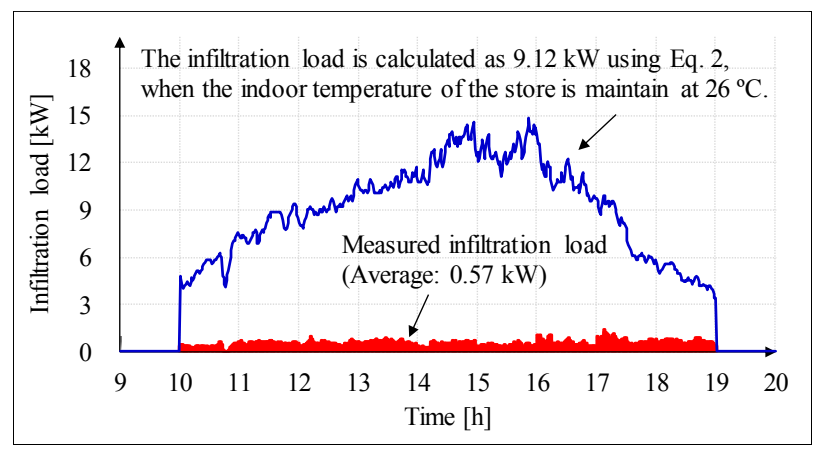

Fig. 12. Infiltration load in case of opened door.

(3) Although the electric power consumption was not increased in case of opened door in target store, the indoor thermal environment is deteriorated. That is also probably because not only the cooling capacity of the air conditioner but also the problem in the arrangement position and airflow direction of the air conditioner.

(4) To business with the door open while air conditioner running in summer, it is necessary for additional consideration of the infiltration load with opening door to design for air conditioning.

This study was partially supported by the Ministry of Education, Science, Sports and Culture in Japan, Grant-in-Aid for Scientific Research (B), 2017-2018 (17K14770). The author would like to express special thanks to its financial and technical support for this study.

\section{References}

1. ASHRAE Handbook, Heating, Ventilating, and AirConditioning Applications, Retail facilities, American Society of Heating, Refrigerating and Air-Conditioning Engineers (ASHRAE) Inc., p.2.1-2.8 (2015).

2. The New York City Council, A Local Law to amend the administrative code of the city of New York in relation to the use of air conditioning systems, Law number 2015/092 (2015).

3. ISO12569:2017, Thermal performance of buildings and materials - Determination of specific airflow rate in buildings - Tracer gas dilution method (2017).

4. Pham Q.T., and Oliver D.W., Infiltration of air into cold stores. Proceedings 16th International Congress of Refrigeration, France, Volume 4, p.67-72 (1983). 